\title{
Newcastle Disease Virus Induced Pathologies Severely Affect the Exocrine and Endocrine Functions of Pancreas in Chickens
}

\section{Zaib Ur Rehman}

University of Arid Agriculture https://orcid.org/0000-0002-8109-797X

Shanhui Ren

Chinese Academy of Agricultural Sciences

\section{Salman Latif Butt}

University of Georgia College of Veterinary Medicine

\section{Muhammad Naveed Anwar}

Chinese Academy of Agricultural Sciences

\section{Yingjie Sun}

Chinese Academy of Agricultural Sciences

\section{Zahid Manzoor}

PMAS Arid Agriculture University: University of Arid Agriculture

\section{Xusheng Qiu \\ Chinese Academy of Agricultural Sciences}

\section{Tan Li}

Chinese Academy of Agricultural Sciences

\section{Ying Liao}

Chinese Academy of Agricultural Sciences

\section{Cuiping Song}

Chinese Academy of Agricultural Sciences

\section{Weiwei Liu}

Chinese Academy of Agricultural Sciences

Chunchun Meng ( $\square$ mengcc@shvri.ac.cn)

Shanghai Veterinary Research Institute (SHVRI), Chinese Academy of Agricultural Sciences (CAAS), Shanghai, 200241, China

\section{Chan Ding}

Chinese Academy of Agricultural Sciences

\section{Research}

Keywords: Newcastle disease virus, chicken, pancreas, hormone, enzymes, histopathology

Posted Date: October 23rd, 2020

DOI: https://doi.org/10.21203/rs.3.rs-95709/v1

License: (-) (1) This work is licensed under a Creative Commons Attribution 4.0 International License. Read Full License

Version of Record: A version of this preprint was published at Genes on March 29th, 2021. See the published version at https://doi.org/10.3390/genes12040495. 


\section{Abstract}

Background: Newcastle disease virus (NDV) causes a highly contagious and devastating disease in poultry, Newcastle disease (ND), which is particularly characterized by extensive pathologies in the digestive, respiratory and nervous systems. ND cause heavy economic losses to the world poultry industry by decreasing growth rate, decrease egg productions, mortality and morbidity. Although, significant advances have been made in the vaccine development, but outbreaks are reported in vaccinated birds leading decrease growth rate.

Methods: In this study, we report the damage caused by the NDV infection in the pancreas of vaccinated as well specific pathogen free chickens.

Results: The histopathological examination of the pancreas showed sever damage in the form of partial depletion of zymogen granules, acinar cell vacuolization, necrosis, and apoptosis, congestion in the large and small vessels, sloughing of epithelial cells of pancreatic duct, and mild perivascular edema. Increased plasma levels of corticosterone, somatostatin, were observed in NDV infected chicks at 3 and 5-day post infection (DPI). Slight decrease in the plasma concentrations of the insulin were noticed at 5 DPI. Significant changes were not observed in the plasma levels of glucagon. Furthermore, NDV infection has decreases the activity and mRNA expression of amylase, lipase, and trypsin from the pancreas.

Conclusion: Taken together, our findings highlight that NDV induces extensive tissue damage in pancreas, decrease the activity and expression of pancreatic enzymes and increase plasma corticosterone and somatostatin.

\section{Background}

Newcastle disease (ND) is highly infectious and one of the most distressing viral diseases of poultry, leading to the heavy economic losses to the world poultry industry [1]. ND is caused by the virulent strains of Avian orthoavulavirus 1 (AOAV-1), also known as ND virus (NDV) [2]. AOAV-1 belongs to the to the order Mononegavirales, family Paramyxoviridae, and genus orthoavulavirus, and contains non-segmented, negative-sense, and single stranded RNA genome of $15 \mathrm{~kb}$ length [3]. The proteins encoded by the AOAV-1 genome are fusion $(F)$, haemagglutinin-neuraminidase $(H N)$, matrix $(M)$, phosphoprotein $(P)$, and large polymerase $(L)$. From these proteins, $F$ and $\mathrm{HN}$ are mainly involved in the AOAV-1 induce pathologies in poultry.

There are four pathotypes of AOAV-1; asymptomatic enteric, lentogenic, mesogenic, and velogenic [4]. Mesogenic and velogenic strains of AOAV- 1 are responsible for the systemic infections in poultry, and clinical manifestations of variable mortality from subclinical infections to 100 percentages. ND mainly affect the digestive, respiratory and nervous system [5-8], but not limited to these organs. AOAV-1 induced pathologies and replication had been noted in spleen, liver, bursa of Fabricious, heart, reproductive system [9-13]. Previous outbreaks of AOAV-1 in vaccinated as well as non-vaccinated poultry had reported the involvement of pancreas $[12,14,15]$.

It is well known that ND decreases the growth rate and egg production for long period in infected chickens [16]. However, AOAV-1 induced pathological changes on the digestion and absorption of nutrients remain elusive. For the digestion of lipids, proteins, carbohydrates, and nucleic acids; different enzymes are produced by the digestive system including salivary glands, intestine, liver, and pancreas [17]. Pancreatic enzymes such as trypsinogen, chymotrypsinogen, elastase and procarboxypeptidases for the digestion of proteins; pancreatic amylase for the digestion of carbohydrates; phospholipase, lipase, and cholesterol esterase for the digestion of lipids; and two type of nucleolytic enzymes namely ribonuclease and deoxyribonuclease [17-20]. The endocrine pancreatic tissue have clusters of cells known as islets of Langerhans, which produce different hormones including insulin, glucagon, somatostatin, and avian pancreatic polypeptide (APP) [21]. These hormones regulate the glucose homeostasis, glucose and amino acid transport, lipogenesis, glycogenolysis, hypoglycerolemia, regulate the level of plasma free fatty acid, regulate the expression of lipogenic enzymes, intestinal motility, and gall bladder secretions [21].

Previous studies have shown the involvement of pancreas in NDV infection and histopathological lesions were reported in chickens $[12,14,22,23]$, ducks [2, 24], geese [25], and turkeys [26]. However, the endocrine and exocrine functions of the pancreas are not clear in NDV infected chickens. Therefore, present study was planned to investigate the pathophysiology of pancreatic functions in NDV infected specific-pathogen-free (SPF) and vaccinated and then NDV challenged chickens.

\section{Methods}




\section{Virus}

A wild type velogenic NDV isolate, ZJ1, (Goose/China/ZJ1/2000; GB AF431744.3), and was obtained from Professor Xiufan Liu from Yangzhou University (Yangzhou, China). The pathogenicity indices including mean death time (MDT), intracerebral pathogenicity index (ICPI), and intravenous pathogenicity index (IVPI) of the ZJ1 were 51.6, 1.89, and 2.7, respectively [27, 28]. The virus stock was prepared by growing the virus in 10-day-old SPF embryonated chicken eggs and harvested allantoic fluid was subsequently stored at $80^{\circ} \mathrm{C}$ until use.

\section{Chickens and Experimental design}

Specific pathogen free embryonated eggs were purchased from the Merial Vital Laboratory Animal Technology Company (Beijing, China) and were incubated at the laboratory facility of SHVRI, CAAS. The hatched-out SPF chicks were reared, vaccinated, and challenged in positive pressure isolators in high containment facility. All the birds were provided with ad libitum access to feed and water throughout the experiment. At the age of 9 weeks, chickens were randomly divided into three groups having 20 chicken each.

Birds in the group $3(\mathrm{VAC}+\mathrm{CHA})$ were vaccinated at the age of 9 weeks with $100 \mu \mathrm{l}$ of LaSota at the dose rate of $10^{3}$ embryo infective dose $\left(E_{50}\right)$ via intranasal and eye drop routs, prepared in phosphate buffered saline (PBS). After 2 week of vaccination of VAC $+\mathrm{CHA}$ group, all the birds in group $2(\mathrm{CHA})$, and VAC + CHA group were challenged with ZJ1 suspended in ice cold PBS have a titer of $10^{6.5}$ $E_{50}$ per bird via right eye and choanal slit in $100 \mu \mathrm{l}$ volume. Dose of the challenged and vaccinated viruses were selected on the basis of previous experiment of Cornax et al. [29]. Birds in the group 1 (CON) were given the same dose of PBS, via the same routs, as a mock infection.

\section{Sampling}

Four birds per group were randomly selected for collection of blood and tissue samples. Blood samples were collected from the jugular vein at 1,3 , and 5 days post infection (DPI) in EDTA-coated tubes, and immediately transferred to the laboratory, maintaining the cold chain. To obtain the plasma, blood samples were centrifuged $(2000 \times \mathrm{g})$ for $10 \mathrm{~min}$ at $4{ }^{\circ} \mathrm{C}$ and stored at $-80{ }^{\circ} \mathrm{C}$ until further analysis. A total of four chickens per experimental treatment were sacrificed for the collection of pancreatic tissue at 1, 3, and $5 \mathrm{DPI}$. All the tissue samples were immediately put in liquid nitrogen and stored at $-80{ }^{\circ} \mathrm{C}$ until further analysis.

\section{Plasma hormones}

Plasma levels of the somatostatin, insulin and glucagon were determined by using chicken specific commercial assay kits [Nanjing Jiancheng Bioengineering Institute (H092-SS; H183 GC; H203 Insulin)]. All samples were analyzed within single assay to avoid interassay variations. The absorbance of the microplates was determined using the Epoch microplate spectrophotometer (BioTek Instruments, Inc., Winooski, VT, USA) at the optical density value of $450 \mathrm{~nm}$. The plasma levels of corticosterone (CORT) were measured using a chicken specific commercial ELISA kit (CSB-E11991C; Cusabio Biotech. Co., Ltd., Wuhan, China). The standard curve was made by using the CurveExpert 1.4. The limits of detection for the insulin and glucagon were $0.5 \mathrm{mlU} / \mathrm{ml}$ and $5 \mathrm{ng} / \mathrm{L}$, respectively. The inter and intra assay coefficient of variation was less than $10 \%$ and $12 \%$ respectively.

\section{Digestive enzyme activities in pancreas}

To determine the activity of the pancreatic enzymes, a small portion (about $1 \mathrm{mg}$ ) of the pancreatic tissue was homogenized in 9 volumes (W/V) of ice-cold phosphate buffer saline (PBS), using a Tissuelyser-24 (Jingxin Technology, Shanghai, China) at $20 \mathrm{~Hz}$ for 2 minutes, and instantly centrifuged at $3000 \times \mathrm{g}$ at $4{ }^{\circ} \mathrm{C}$ for 10 minutes. The supernatant was collected for the determination of digestive enzyme activities. To determine the activity of trypsin (A080), lipase (A054) and amylase (C016) by calorimetric methods, commercial kits were used (Nanjing Jiancheng Bioengineering Institute, China). Pre-experimental standardizations were performed for each of the targeted enzyme to determine the optimum dilution for the measurement of enzymes. Protein concentration of the supernatants were determined by using the kits from Beyotime, (Beyotime, Nanjing, China; P0010).

\section{Total RNA extraction and quantitative real-time PCR}

The quantitative real time PCR (qRT-PCR) was performed to measure the mRNA expressions of pancreatic digestive enzymes including amylase, lipase, and trypsin genes. The chicken glyceraldehyde 3-phosphate dehydrogenase (GAPDH) was used as internal control. The primers used in the present study were synthesized by Sangon Biotech Co., Ltd (Shanghai, China) and are described in the Table 1. Total RNA of the pancreas samples were extracted by using TRIzol reagent (Invitrogen, Carlsbad, CA, USA) according to the 
manufacturer's protocol. RNA pellet was dissolved in RNase-free water. Total RNA was quantified using a NanoDrop spectrophotometer (Thermo Fisher Scientific, Waltham, MA, USA) and purity was assessed by measuring the absorbance ratio at 260 to $280 \mathrm{~nm}$. Reverse transcription was performed using HiScript II (Catalogue \# R233; Vazyme Biotech Co., Ltd., China), according to the manufacturer's instructions. Expression of target genes were measured by performing the qRT-PCR on CFX96 Touch Real-Time PCR Detection System (BioRad, USA), using SYBR Premix (Dongsheng, Biotech, China), and data were normalized with GAPDH. The qRTPCR was performed with a final volume of $20 \mu$ l. The PCR cycles are as follows: $94{ }^{\circ} \mathrm{C}$ for 3 minutes, followed by 40 cycles of $95^{\circ} \mathrm{C}$ for $15 \mathrm{~s}, 60{ }^{\circ} \mathrm{C}$ for $15 \mathrm{~s}$ and $72{ }^{\circ} \mathrm{C}$ for $20 \mathrm{~s}$. All the amplifications generated expected amplicons with single, sharp fusion curves. All experiments were carried out in triplicate. The changes of mRNAs were presented as fold expression and calculated using $2^{-\triangle \Delta C T}$ method [30].

Table 1

List of primer sequences used for quantitative PCR.

\begin{tabular}{|lllll|}
\hline $\begin{array}{l}\text { Gene } \\
\text { Type }\end{array}$ & Forward Primer(5'-3') & Reverse primer(5'-3') & $\begin{array}{c}\text { Amplicon } \\
\text { size (bp) }\end{array}$ & $\begin{array}{l}\text { Gen Bank } \\
\text { accession } \\
\text { number }\end{array}$ \\
\hline $\begin{array}{l}\text { ZJ1 M } \\
\text { gene }\end{array}$ & ATGGACTCATCCAGGACAATCGGGCT & TTATTTCCTGAAAGGATTGTATTTAGCAATGG & 1095 & AF431744.3 \\
\hline $\begin{array}{l}\text { ZJ1 M } \\
\text { gene }\end{array}$ & TACTTTGATTCTGCCCTCCCTT & TAAGCAGAGCATTGCGGAAGA & 255 & AF431744.3 \\
\hline Trypsin & GTCGCCTTTGTTGGTGTGAC & GCTGATGAGAGAGCCTCCAC & 150 & NM_205385 \\
\hline Lipase & AGGAGAAGAAGGCTGGACCT & TCAGCACCTACAACACGGAC & 141 & XM_015288675 \\
\hline Amylase & TCAGGCTGGGAGGACATCTA & CCAGGGCCTGTTCGGATTAG & 157 & NM_001001473 \\
\hline GAPDH & CCATCACAGCCACACAGAAGAC & TGGACGCTGGGATGATGTT & 93 & NM_204305 \\
\hline
\end{tabular}

\section{Viral loads in the pancreas}

The virus copy numbers were detected from the pancreas as described previously [9]. Briefly, the ZJ1 strain was grown in 10-day-old SPF embryonated eggs and allantoic fluid was collected after $60 \mathrm{~h}$ of infection. The TRIzol (Invitrogen, Carlsbad, CA, USA) reagent was used to extract the viral RNA from the allantoic fluid as per the manufacturer's instructions. The ZJ1 M gene was amplified using the primers mentioned in the Table 1, and confirmand the size (1095 bp) of the fragment by electrophoresis. The HiPure Gel Pure DNA Mini Kit (AnGen Biotech, Guangzhou, China) was used to purify the PCR product and cloned into a plasmid vector to construct a standard curve. The pancreatic tissue from the chickens was homogenized and RNA was extracted as mentioned above. About $1 \mu \mathrm{g}$ RNA extracted from the pancreas samples was reverse transcribed to cDNA with HiScript II (Catalogue \# R233; Vazyme Biotech Co., Ltd., China), and quantitative PCR was performed with SYBR Premix (Dongsheng, Biotech, China). Virus copy numbers were calculated using the standard curve [9].

\section{Histopathology}

Samples of the Pancreatic tissue were collected from the middle region and fixed in $10 \%$ neutral buffered formalin, embedded in paraffin. and $5 \mu \mathrm{m}$ thick sections were obtained. The sections were stained with hematoxylin and eosin (H\&E) following the standard procedures [31]. The slides were digitalized by using Pannoramic SCAN (3DHISTECH Ltd., Hungary) and histological lesions were studied by using CaseViewer 2.2 (3DHISTECH Ltd., Hungary) [32].

\section{TUNEL assay}

For the detection of apoptotic cells, $5 \mathrm{~mm}$ thick tissue sections of the pancreas were subjected to the transferase dUTP nick-end labeling (TUNEL) assay according to the manufacturer's instructions (Roche Diagnostics GmbH, Mannheim, Germany). Tissue sections were deparaffinized and rehydrated by the graded levels of xylene and ethanol. Tissue sections were treated with proteinase $\mathrm{K}$ and incubated at $37^{\circ} \mathrm{C}$ for $25 \mathrm{~min}$. Activity of the endogenous peroxidase activity was blocked with hydrogen peroxide. The sections were incubated at $37^{\circ} \mathrm{C}$ with the terminal TdT nucleotide mixture for 2 hours. Nuclei were counterstained with $3 \mu \mathrm{g} / \mathrm{ml} \mathrm{4} 4^{\prime}, 6^{\prime}$-diamidine2-phenylindole (DAPI) and visualized by using fluorescence microscopy. Then slides were digitalized by using Pannoramic SCAN (3DHISTECH Ltd., Hungary), and studied by using CaseViewer 2.2 (3DHISTECH Ltd., Hungary). Five different high power fields (HPF) were selected to count the number of apoptotic cells using Image-Pro Plus software (version 6.0 for Windows). 


\section{Statistical analysis}

The data were analyzed by two-way ANOVA test, with challenge and time points as the main effects [33], and Graph Pad Prism 6.0 software (GraphPad Software, Inc., CA, USA) was used to generate the graphs. The graphical results were expressed as mean \pm standard deviation $(M \pm S D)$. Results with $P<0.05$ were considered as statistically significant. When a significant main effects was observed, TUKEY test was used to compare the differences among groups.

\section{Results}

\section{Viral load in the pancreas}

The transcriptional level of the NDV M gene was determined to examine the viral load in the pancreas using the qRT-PCR assay at 3 and $5 \mathrm{DPI}$. The viral copy numbers per $\mu \mathrm{l}$ are shown in the Fig. 1. There was non-significant difference in the viral load of VAC + NDV and CHA groups at $3 \mathrm{DPI}$ and viral copy numbers were significantly less at 3DPI compared to 5 DPI in infected groups. Maximum viral load observed in the CHA group at $5 \mathrm{DPI}$ and was significantly higher compared to VAC + NDV group. The negative control group remained negative for NDV.

\section{Histopathology}

There were not significant changes observed in the control group. At certain locations, presence of intranuclear eosinophilic material could be nuclear edema or nuclear invagination or incidental finding. In CHA group, at 1 DPI, pancreas was intact, multifocal lymphoid nodules in the proximity of branches of pancreatic ducts, and occasionally, hyperplasia in the endocrine pancreas was seen. Rarely, cells in the acinar tissue had eosinophilic intranuclear material. This was only observed in the endocrine tissues. There was mild perivascular edema. Rare multifocal apoptotic cells (rounded, hypereosinophilic with pyknotic nuclei) were noticed. At 3 DPI, in CHA group, eosinophilic intranuclear material was noticed in endocrine pancreas. Multifocal to diffusely, there was partial depletion of zymogen granules form the exocrine pancreas. Acinar cells had occasional single to multiple vacuoles in the apical portion of the cell. Multifocally, there was mild perivascular edema and occasionally individualization of acinar cells. Few acinar cells undergo single cell necrosis/apoptosis and other cells had mild cytoplasmic vacuolation. No significant changes were observed in the endocrine pancreas. Occasionally, there was lymphocytic infiltration in the exocrine tissue. Rarely, there were eosinophilic intranuclear inclusion bodies in the endocrine tissue (Fig. 2, E). At 5 DPI, in CHA group, exocrine cells had a complete loss of zymogen granules, rounded off, and separated from neighboring cells. The exocrine and endocrine tissues had lost the original structure, and cells were individualized. There was sever congestion in the large and small vessels. The epithelial cells of pancreatic duct were sloughed and lost nuclear detail as well. There was mild perivascular edema. Occasionally single cell necrosis (Fig. 2, H). There was cytoplasmic vacuolation of acinar cells in the exocrine tissue and partial depletion of zymogen granules.

In VAC + CHA group, at 1 DPI pancreatic tissue shad, multifocal, partial to complete depletion of zymogen granules, cytoplasmic vacuolation (degeneration) and sometimes necrosis of individual acinar cells of pancreas. At $3 \mathrm{DPI}$, the acinar cells undergo a spectrum of changes that range from degeneration, with loss of zymogen granules, cytoplasmic vacuolation and swelling of the cells, to single cell necrosis, with cells becoming individualized, and shrunken with pyknotic nuclei. There were multifocal, randomly distributed lymphoid nodules. Whereas at 5 DPI, partial or complete depletion of zymogen granules were observed. Frequently, cytoplasmic vacuolation with eosinophilic hyaline inclusion in acinar cells of pancreas were seen throughout the exocrine part. There were multifocal lymphoid nodules throughout exocrine pancreas. There was marked increase in the cytoplasmic vacuolation and single cell necrosis of acinar cells and due to partial depletion of zymogen granules, acinar cells looked ductless. There is mild to moderate interstitial edema in exocrine portion of pancreas and separation of acinar cells from neighboring cells. One focal area of lymphocytic infiltration in the peripancreatic duct branch, perivascular edema was observed. Persistently, scattered lymphocytes were observed throughout the exocrine pancreas. Most of the observed lesion were perivascular in this slide (Fig. 2, I). Individualized round acinar cells with dark pyknotic nuclei showed sever single cell necrosis throughout the exocrine tissue. There was distortion of the acinar cells and separation from the neighboring cells. Diffusely, the areas of cytoplasmic vacuolation of acinar cells are seen.

\section{Apoptosis in the pancreas}

To estimate NDV induced apoptosis in the chicken pancreatic tissue, TUNEL positive cells were counted (Fig. 3). The apoptotic cells had green stained nuclei. As presented in the Fig. 3A, the number of apoptotic positive cells in the pancreas was similar between the CON and NDV infected groups at 1 DPI. In the NDV challenged groups, the number of apoptotic cells were significantly increased

Page 5/16 
compared to CON at 3DPI. The increase in the number of apoptotic cells was less evident in the VAC + NDV group compared to CHA, but, still it was significantly higher than the CON (Fig. 3, B) at 5 DPI.

\section{Plasma concentrations of hormones}

The plasma concentrations of CORT were significantly elevated $(P<0.05)$ in the CHA group compared to CON at 3 DPI. Significant difference was not found in the concentrations of CORT in CON and VAC + CHA (Fig. 4, A). However, at 5 DPI, NDV challenge had significantly increased the plasma CORT level in CHA and VAC + CHA groups compared to the CON group.

Plasma concentrations of the glucagon and insulin are represented in the Fig. 4 (B, C respectively). Statistically, non-significant effect of NDV challenge on glucagon was observed at 3 and 5 DPI, but numerically, slight decrease in the plasma levels of NDV infected birds were noticed compare to $\mathrm{CON}$ group. The plasma levels of insulin remained unaffected at $3 \mathrm{DPI}$, but significant decrease was observed in CHA group compared to control at 5 DPI (Fig. 4, C).

Plasma concentration of the somatostatin is presented in the (Fig. 4, D). The plasma concentrations of the somatostatin were significantly increased $(\mathrm{P}<0.05)$ in CHA (from 261114c) group but, this increase was not significant in CON and VAC + CHA groups, at 3 DPI. Birds in the CHA group tends to have higher concentration $(P<0.05)$ of somatostatin at 5 DPI compared to CON and VAC + CHA groups.

\section{Activity and expression of pancreatic enzymes}

The results for amylase activity and expression are presented in Fig. 5 (A, B). At 3 DPI, chickens in the CHA group showed decreased activity of amylase $(p<0.05)$, compared to the CON group. However, amylase activity in the pancreas of the VAC + CHA group of chickens was similar to that observed in the CON group, at 3DPI. More drastic decrease in the activity and expression of amylase in the pancreas of CHA groups of chickens were observed at 5 DPI compared to CON and VAC + CHA group. Furthermore, activity of amylase in the VAC + CHA was significantly less than control and, more than CHA group. The expression of amylase at $5 \mathrm{DPI}$ from the $\mathrm{CHA}$ and $\mathrm{VAC}+\mathrm{CHA}$ groups were significantly $(\mathrm{p}<0.05)$ less than the CON group.

There was non-significant effect of NDV challenge in SPF and vaccinated chickens on the activity of lipase at 3 DPI (Fig. 5, C). NDV infection in SPF chickens resulted in decrease activity of lipase compared to chickens in the CON and VAC + CHA groups. Lipase mRNA expression in the pancreas had significantly decreased in NDV infected birds $(p<0.05)$, compared to CON at 3 , and 5 DPI (Fig. 5, D).

The NDV challenge significantly affected the activity and expression of pancreatic trypsin (Fig. 5, E, F). Activity of trypsin was significantly decreased in NDV challenge groups compared to CON, and this decrease was more obvious at $5 \mathrm{DPI}$. The mRNA expression of trypsin was significantly higher in the pancreas of CON birds $(p<0.05)$, compared to CHA and VAC + CHA groups.

\section{Discussion}

The present study comprehensively reported the effect of NDV infection on the pancreas in vaccinated as well as SPF chickens. We persuasively demonstrated the replication of NDV in the pancreas of chicken in vaccinated and SPF chickens. In the study, chickens were vaccinated with $10^{3}$ EID50 of the Lasota and challenged with $10^{6.5} \mathrm{EID}_{50}$ of the ZJ1 after 2 week of vaccination because, at this dose of vaccine and challenge, pathogenic virus can replicate, can cause conjunctivitis and mild depression \{Cornax, $2012 \# 1671$ \}. Histological studies of the chickens in the current experiment advocate the severe damage caused by the NDV in the pancreas. The NDV infection had caused the partial depletion to complete loss of zymogen granules form the exocrine pancreas, cytoplasmic vacuolation and necrosis of acinar cells cell, and eosinophilic intranuclear material was noticed in endocrine pancreas, but these were less evident at 3 DPI compared to 5 DPI. Histopathological results of the present study are in agreement with the previous studies [12, $14,22-24]$.

The NDV infection in vaccinated as well as SPF chicken resulted in significant decrease in the activities and expression of pancreatic enzymes. These decreased activities and expression of amylase, lipase and trypsin may be related to extensive damage caused by the NDV to exocrine portion of pancreas in the infected birds. These decreased activities of the pancreatic enzymes may be one of the insults to decrease the digestion and weight gain in NDV infected vaccinated birds. Decrease activities of the digestive enzyme may be related to poor production performance after NDV outbreaks in commercial poultry. Our hypothesis was that chickens having less vaccine dose can suffer with pancreatitis which may leads to decrease production of digestive enzyme. 
It is well studied, that hypothalamic-pituitary-adrenal axis is involved in acute stress and regulate the inflammatory response to an infectious challenge. Stress is strongly correlated with the exacerbation of many viral infections [34, 35]. In this study increased plasma levels of corticosterone were found in NDV infected chicken. Increased levels of corticosterone have been related to decrease growth rate, decreased antibody response, decreased number of lymphocytes, and reduced size of lymphoid organs [36].

Corticosterone decrease the insulin sensitivity in chicken [37]. In this study slight decrease in the plasma level of insulin and glucagon was noted at 5 DPI in NDV infected chicken. It may be due to less structural and morphological changes in the endocrine pancreas after NDV infection, as noted in the histopathology results. Avian pancreas has higher levels of glutathione, which exhibits protective effects on the beta cells [38]. This increased level of glutathione may be related to less pathogenicity in the endocrine pancreas because, decreased levels of glutathione was observed in the plasma and intestines of NDV infected chickens [6, 39].

The somatostatin, also known as growth hormone-inhibiting hormone, is a 14 amino acid peptide that regulates the endocrine system. Somatostatin is produced by the delta cells ( $\delta$-cells or D cells)[40]. Previous studies had suggested the production of SS from the endocrine cells in the proventriculus, small intestine [41], pancreas [42] and expression in the testis [43]. There are two forms of chicken somatostatin, somatostatin-14 and somatostatin-28, which are encoded by the same gene (PSS1) but another variant exist which is expressed in the brain and pancreatic islets [21,44]. The somatostatin inhibits the production of many hormones including insulin, glucagon, growth hormone, gastrin, vasoactive intestinal peptide, and thyroid-stimulating hormone [45]. In the present study, increase plasm levels of somatostatin were found in NDV challenged birds. Increased somatostatin mRNA expression has been described after stimulation with cytokines in murine macrophage [46]. Similarly, increased plasma concentration of somatostatin in endotoxin injected sheep [47], septic pigs [48], simian immunodeficiency virus infected macaque, then infected with Mycobacterium Avium [49], increased expression in rabies virus infected brain [50] and secreted by human adipocytes after stimulation with activated macrophages, LPS, and IL-1 [51]. The increased plasma concentrations of somatostatin may be involved to counter the inflammation caused by infection. The SS has been described as anti-inflammatory and immunosuppressive and its analogues have been used as potential treatments for inflammation $[52,53]$.

\section{Conclusions}

In summary, present study suggest that the pancreas could be a potential target of NDV infection. Evidently, exocrine pancreas is more severely affected by NDV compared to endocrine pancreas. The NDV infection leads to decrease in production and activity of digestive enzyme from the pancreas, even in the vaccinated chickens. Similarly, NDV infection also induce the increased levels of corticosterone and somatostatin, and decreased the production of insulin as evident from the plasma levels. These pathologies of the pancreas may be the leading cause of decreased production performance of NDV infected vaccinated birds.

\section{Abbreviations}

ND

Newcastle disease

NDV

Newcastle disease virus

DPI

day post-infection

AOAV-1

Avian orthoavulavirus 1

$\mathrm{F}$

fusion;

$\mathrm{HN}$

haemagglutinin-neuraminidase

$\mathrm{M}$

matrix

$\mathrm{P}$

phosphoprotein

SS

somatostatin; 
APP

avian pancreatic polypeptide

SPF

specific-pathogen-free

SHVRI

Shanghai Veterinary Research Institute (Shanghai, China)

CAAS

Chinese Academy of Agricultural Sciences

CON

control

$\mathrm{CHA}$

Newcastle disease virus challenged

$\mathrm{VAC}+\mathrm{CHA}$

vaccinated with LaSota and challenged with virulent Newcastle diseases virus after 2 weeks of vaccination

$\mathrm{EID}_{50}$

embryo infective dose 50 percentage

CORT

corticosterone

TUNEL

dUTP nick-end labeling

DAPI

$3 \mu \mathrm{g} / \mathrm{ml} \mathrm{4',} \mathrm{6'-diamidine-2-phenylindole}$

$H \& E$

hematoxylin and eosin

GAPDH

glyceraldehyde 3-phosphate dehydrogenase

\section{Declarations}

\section{Ethics approval and consent to participate}

All the animal experimental procedures were performed in strict accordance with the recommendations in the Guide for the Care and Use of Laboratory Animals of Shanghai Veterinary Research Institute (SHVRI, Shanghai, China), of the Chinese Academy of Agricultural Sciences (CAAS, Beijing, China). All protocols applied in this study were approved by the Institutional Animal Care and Use Committee (IACUC) of SHVRI (Permission number: SHVI-RO-2018030189), CAAS, China. All efforts were made to minimize the suffering of experimental birds.

\section{Consent to publish}

Not applicable.

\section{Availability of data and materials}

Data supporting the conclusions of this article are included within the article.

\section{Competing interests}

The authors declare that they have no competing interests.

\section{Funding}


These authors are funded by the National Key Research and Development Program of China (no. 2018YFD0500100), National Natural Science Foundation of China (no.31530074), and Shanghai Key Laboratory of Veterinary Biotechnology (no. klab201702). The funders had no role in study design, data collection and interpretation, or the decision to submit the work for publication.

\section{Authors' contributions}

ZUR conceived, designed, performed the experiments, and wrote the manuscript; SR, MNA and YS helped in the animal experiments and sample collection, XQ, SR, LT, YL, CS, WL, YS, and CM helped in the lab experiments; AA, SR, and ZUR, analyzed the data; SLB read and described the histological slides, and proof read the manuscript; CM and CD supervise the study, and contributed the reagents/materials/analysis tools. All authors read and approved the final manuscript.

\section{Acknowledgments}

The authors would like to thank Patti J. Miller and Claudio L. Afonso (Southeast Poultry Research Laboratory, 934 College Station Road, Athens, GA 30052, USA) for their assistance in the designing of vaccination model. We also thank the staff of animal experiment facility of Shanghai Veterinary Research Institute.

\section{References}

1. Alexander DJ (2003) Newcastle disease. In: Saif, Y.M., Barnes, H.J.,Glisson, J.R., Fadly, A.M., McDougald, L.R., Swayne, D.E. (Eds.), Disease of Poultry. lowa State Press, Ames, IA, pp. 64-87.

2. Rehman ZU, Meng C, Sun Y, Mahrose KM, Umar S, Ding C, Munir M (2018) Pathobiology of Avian avulavirus 1: special focus on waterfowl. Vet Res 49 (1):94. doi:10.1186/s13567-018-0587-x

3. Dimitrov KM, Abolnik C, Afonso CL, Albina E, Bahl J, Berg M, Briand F-X, Brown IH, Choi K-S, Chvala I, Diel DG, Durr PA, Ferreira HL, Fusaro A, Gil P, Goujgoulova GV, Grund C, Hicks JT, Joannis TM, Torchetti MK, Kolosov S, Lambrecht B, Lewis NS, Liu H, Liu H, McCullough S, Miller PJ, Monne I, Muller CP, Munir M, Reischak D, Sabra M, Samal SK, Servan de Almeida R, Shittu I, Snoeck CJ, Suarez DL, Van Borm S, Wang Z, Wong FYK (2019) Updated unified phylogenetic classification system and revised nomenclature for Newcastle disease virus. Infect Genet Evol 74:103917. doi:https://doi.org/10.1016/j.meegid.2019.103917

4. Cattoli G, Susta L, Terregino C, Brown C (2011) Newcastle disease: a review of field recognition and current methods of laboratory detection. J Vet Diagn Invest 23 (4):637-656. doi:10.1177/1040638711407887

5. Meng C, Rehman ZU, Liu K, Qiu X, Tan L, Sun Y, Liao Y, Song C, Yu S, Ding Z, Nair V, Munir M, Ding C (2018) Potential of genotype VII Newcastle disease viruses to cause differential infections in chickens and ducks. Transbound Emerg Dis 65 (6):1851-1862. doi:10.1111/tbed.12965

6. Rehman ZU, Qiu X, Sun Y, Liao Y, Tan L, Song C, Yu S, Ding Z, Munir M, Nair V, Meng C, Ding C (2018) Vitamin E Supplementation Ameliorates Newcastle Disease Virus-Induced Oxidative Stress and Alleviates Tissue Damage in the Brains of Chickens. Viruses 10 (4):173. doi:10.3390/v10040173

7. Butt SL, Moura V, Susta L, Miller PJ, Hutcheson JM, Cardenas-Garcia S, Brown CC, West FD, Afonso CL, Stanton JB (2019) Tropism of Newcastle disease virus strains for chicken neurons, astrocytes, oligodendrocytes, and microglia. BMC Vet Res 15 (1):317. doi:10.1186/s12917-019-2053-z

8. Ecco R, Susta L, Afonso CL, Miller PJ, Brown C (2011) Neurological lesions in chickens experimentally infected with virulent Newcastle disease virus isolates. Avian Pathol 40 (2):145-152. doi:10.1080/03079457.2010.544289

9. Rehman ZU, Ren S, Yang B, Yang X, Butt SL, Afzal A, Malik MI, Sun Y, Yu S, Meng C, Ding C (2020) Newcastle disease virus induces testicular damage and disrupts steroidogenesis in specific pathogen free roosters. Vet Res 51 (1):84. doi:10.1186/s13567-02000801-0

10. Hussein EA, Hair-Bejo M, Omar AR, Arshad SS, Hani H, Balakrishnan KN, Yakubu Y, Saeed MI, Aini I (2019) Velogenic newcastle disease virus tissue tropism and pathogenesis of infection in chickens by application of in situ PCR, immunoperoxase staining and HE staining. Microb Pathog 129:213-223. doi:10.1016/j.micpath.2019.02.017

11. Cui N, Huang X, Kong Z, Huang Y, Huang Q, Yang S, Zhang L, Xu C, Zhang X, Cui Y (2018) Newcastle Disease Virus Infection Interferes With the Formation of Intestinal Microflora in Newly Hatched Specific-Pathogen-Free Chicks. Front Microbiol 9 
(MAY):900. doi:10.3389/fmicb.2018.00900

12. Nakamura K, Ohtsu N, Nakamura T, Yamamoto Y, Yamada M, Mase M, Imai K (2008) Pathologic and immunohistochemical studies of Newcastle disease (ND) in broiler chickens vaccinated with ND: severe nonpurulent encephalitis and necrotizing pancreatitis. Vet Pathol 45 (6):928-933. doi:10.1354/vp.45-6-928

13. Susta L, Miller PJ, Afonso CL, Brown CC (2011) Clinicopathological characterization in poultry of three strains of Newcastle disease virus isolated from recent outbreaks. Vet Pathol 48 (2):349-360. doi:10.1177/0300985810375806

14. El-Bahrawy A, Zaid A, Sunden Y, Sakurai M, Ito H, Ito T, Morita T (2015) Pathogenesis of Pancreatitis in Chickens after Experimental Infection with 9a5b Newcastle Disease Virus Mutant Isolate. J Comp Pathol 153 (4):315-323. doi:10.1016/j.jcpa.2015.08.002

15. Meulemans G, Roels S, van den Berg TP, Godfroid J, Decaesstecker M (1998) Acute pancreatitis in chickens due to non-virulent Newcastle disease virus. Vet Rec 143 (11):300-303. doi:10.1136/vr.143.11.300

16. Han Q, Gao X, Wu P, Xiao S, Wang X, Liu P, Tong L, Hao H, Zhang S, Dang R, Yang Z (2017) Re-evaluation the immune efficacy of Newcastle disease virus vaccine in commercial laying chickens. Res Vet Sci 111:63-66. doi:10.1016/j.rvsc.2016.12.004

17. Denbow DM (2015) Chapter 14 - Gastrointestinal Anatomy and Physiology. In: Scanes CG (ed) Sturkie's Avian Physiology (Sixth Edition). Academic Press, San Diego, pp 337-366. doi:https://doi.org/10.1016/B978-0-12-407160-5.00014-2

18. Laws BM, Moore JH (1963) The lipase and esterase activities of the pancreas and small intestine of the chick. Biochem J 87 (3):632-638

19. Mahdavi R, Osmanyan AK, Fisinin VI, Ghazi Harsini S, Arkhipova AL, Shevyakov AN, Kovalchuk SN, Kosovsky GY (2018) Impact of mash and crumble diets on intestinal amino acids transporters, intestinal morphology and pancreatic enzyme activity of broilers. J Anim Physiol Anim Nutr (Berl) 102 (5):1266-1273. doi:10.1111/jpn.12956

20. Yuan L, Wang M, Zhang X, Wang Z (2017) Effects of protease and non-starch polysaccharide enzyme on performance, digestive function, activity and gene expression of endogenous enzyme of broilers. PLoS ONE 12 (3):e0173941. doi:10.1371/journal.pone.0173941

21. Dupont J, Rideau N, Simon J (2015) Chapter 27 - Endocrine Pancreas. In: Scanes CG (ed) Sturkie's Avian Physiology (Sixth Edition). Academic Press, San Diego, pp 613-631. doi:https://doi.org/10.1016/B978-0-12-407160-5.00027-0

22. Kommers GD, King DJ, Seal BS, Brown CC (2003) Pathogenesis of chicken-passaged Newcastle disease viruses isolated from chickens and wild and exotic birds. Avian Dis 47 (2):319-329. doi:10.1637/0005-2086(2003)047[0319:pocndv]2.0.co;2

23. Susta L, Cornax I, Diel DG, Garcia SC, Miller PJ, Liu X, Hu S, Brown CC, Afonso CL (2013) Expression of interferon gamma by a highly virulent strain of Newcastle disease virus decreases its pathogenicity in chickens. Microb Pathog 61-62:73-83. doi:https://doi.org/10.1016/j.micpath.2013.05.009

24. Dai Y, Cheng X, Liu M, Shen X, Li J, Yu S, Zou J, Ding C (2014) Experimental infection of duck origin virulent Newcastle disease virus strain in ducks. BMC Vet Res 10:164. doi:10.1186/1746-6148-10-164

25. Kang Y, Li Y, Yuan R, Li X, Sun M, Wang Z, Feng M, Jiao P, Ren T (2014) Phylogenetic relationships and pathogenicity variation of two Newcastle disease viruses isolated from domestic ducks in Southern China. Virol J 11:147. doi:10.1186/1743-422X-11-147

26. Piacenti AM, King DJ, Seal BS, Zhang J, Brown CC (2006) Pathogenesis of Newcastle disease in commercial and specific pathogen-free turkeys experimentally infected with isolates of different virulence. Vet Pathol 43 (2):168-178. doi:10.1354/vp.43-2168

27. Hu S, Ma H, Wu Y, Liu W, Wang X, Liu Y, Liu X (2009) A vaccine candidate of attenuated genotype VII Newcastle disease virus generated by reverse genetics. Vaccine 27 (6):904-910. doi:10.1016/j.vaccine.2008.11.091

28. Wan H, Chen L, Wu L, Liu X (2004) Newcastle disease in geese: natural occurrence and experimental infection. Avian Pathol 33 (2):216-221. doi:10.1080/0307945042000195803

29. Cornax I, Miller PJ, Afonso CL (2012) Characterization of live LaSota vaccine strain-induced protection in chickens upon early challenge with a virulent Newcastle disease virus of heterologous genotype. Avian Dis 56 (3):464-470. doi:10.1637/10043122011-Reg. 1

30. Livak KJ, Schmittgen TD (2001) Analysis of relative gene expression data using real-time quantitative PCR and the 2(-Delta Delta C(T)) Method. Methods 25 (4):402-408. doi:10.1006/meth.2001.1262

31. Munro B (1971) Manual of histologic staining methods of the Armed Forces Institute of Pathology. Pathology 3 (3):249 
32. Qu Y, Zhan Y, Yang S, Ren S, Qiu X, Rehamn ZU, Tan L, Sun Y, Meng C, Song C, Yu S, Ding C (2018) Newcastle disease virus infection triggers HMGB1 release to promote the inflammatory response. Virology 525:19-31. doi:10.1016/j.virol.2018.09.001

33. Assaad HI, Hou Y, Zhou L, Carroll RJ, Wu G (2015) Rapid publication-ready MS-Word tables for two-way ANOVA. Springerplus 4 (1):33. doi:10.1186/s40064-015-0795-z

34. Owen JC, Nakamura A, Coon CA, Martin LB (2012) The effect of exogenous corticosterone on West Nile virus infection in Northern Cardinals (Cardinalis cardinalis). Vet Res 43 (1). doi:10.1186/1297-9716-43-34

35. Ives AM, Bertke AS (2017) Stress hormones epinephrine and corticosterone selectively modulate herpes simplex virus 1 (HSV-1) and HSV-2 productive infections in adult sympathetic, but not sensory, neurons. J Virol 91 (13). doi:10.1128/JVI.00582-17

36. Gross W, Siegel P, DuBose R (1980) Some effects of feeding corticosterone to chickens. Poult Sci 59 (3):516-522

37. Zhao J, Lin H, Jiao H, Song Z (2009) Corticosterone suppresses insulin-and NO-stimulated muscle glucose uptake in broiler chickens (Gallus gallus domesticus). Comparative Biochemistry and Physiology Part C: Toxicology \& Pharmacology 149 (3):448454

38. Hazelwood RL (2000) CHAPTER 20 - Pancreas. In: Whittow GC (ed) Sturkie's Avian Physiology (Fifth Edition). Academic Press, San Diego, pp 539-555. doi:https://doi.org/10.1016/B978-012747605-6/50021-3

39. Rehman ZU, Che L, Ren S, Liao Y, Qiu X, Yu S, Sun Y, Tan L, Song C, Liu W, Ding Z, Munir M, Nair V, Meng C, Ding C (2018) Supplementation of Vitamin E Protects Chickens from Newcastle Disease Virus-Mediated Exacerbation of Intestinal Oxidative Stress and Tissue Damage. Cell Physiol Biochem 47 (4):1655-1666. doi:10.1159/000490984

40. Guillemin R (1993) Somatostatin: the early days. Digestion 54 Suppl 1:3-6. doi:10.1159/000201066

41. Alison B (1989) The distribution and ontogeny of gastrin/CCK-, somatostatin-and neurotensin-immunoreactive cells in the gastrointestinal tract of the chicken. Histol Histopathol 4 (1):55-62

42. Ku SK, Lee JH, Lee HS (2000) An immunohistochemical study of the insulin-, glucagon- and somatostatin-immunoreactive cells in the developing pancreas of the chicken embryo. Tissue Cell 32 (1):58-65. doi:10.1054/tice.1999.0086

43. Malik N, Moaeen-ud-Din M, Zhao R (2013) Ontogeny of mRNA expression of somatostatin and its receptors in chicken embryos in association with methylation status of their promoters. Comp Biochem Physiol B Biochem Mol Biol 165 (4):260-270. doi:10.1016/j.cbpb.2013.05.006

44. Trabucchi M, Tostivint H, Lihrmann I, Blähser S, Vallarino M, Vaudry H (2003) Characterization of the cDNA encoding a somatostatin variant in the chicken brain: comparison of the distribution of the two somatostatin precursor mRNAs. J Comp Neurol 461 (4):441-451

45. Low MJ (2003) Somatostatin. In: Henry HL, Norman AW (eds) Encyclopedia of Hormones. Academic Press, New York, pp 379-388. doi:https://doi.org/10.1016/B0-12-341103-3/00272-2

46. Elliott DE, Blum AM, Li J, Metwali A, Weinstock JV (1998) Preprosomatostatin messenger RNA is expressed by inflammatory cells and induced by inflammatory mediators and cytokines. J Immunol 160 (8):3997-4003

47. Briard N, Guillaume V, Frachebois C, Rico-Gomez M, Sauze N, Oliver C, Dutour A (1998) Endotoxin injection increases growth hormone and somatostatin secretion in sheep. Endocrinology 139 (6):2662-2669. doi:10.1210/endo.139.6.6072

48. Revhaug A, Lygren I, Lundgren TI, Jorde R, Burhol PG, Giercksky KE (1984) Release of gastrointestinal peptides during E. coli endotoxinaemia. Acta Chir Scand 150 (7):535-539

49. Hendricks EE, Ludlage E, Bussell S, George K, Wegner FH, Mansfield KG (2004) Wasting syndrome and disruption of the somatotropic axis in simian immunodeficiency virus-infected macaques with Mycobacterium avium complex infection. $J$ Infect Dis 190 (12):2187-2194. doi:10.1086/425904

50. Weihe E, Bette M, Preuss MA, Faber M, Schafer MK, Rehnelt J, Schnell MJ, Dietzschold B (2008) Role of virus-induced neuropeptides in the brain in the pathogenesis of rabies. Dev Biol (Basel) 131:73-81

51. Linscheid P, Seboek D, Müller B, Zulewski H, Christ-Crain M, Keller U, Langer I (2004) Somatostatin Is Expressed and Secreted by Human Adipose Tissue upon Infection and Inflammation. The Journal of Clinical Endocrinology \& Metabolism 89 (10):4833-4839. doi:10.1210/jc.2004-0271

52. Takeba Y, Suzuki N, Takeno M, Asai T, Tsuboi S, Hoshino T, Sakane T (1997) Modulation of synovial cell function by somatostatin in patients with rheumatoid arthritis. Arthritis Rheum 40 (12):2128-2138. doi:10.1002/1529-0131(199712)40:12<2128::Aid-

art5>3.0.Co;2-s

Page $11 / 16$ 
53. Sakane T, Suzuki N (1998) The role of somatostatin in the pathophysiology of rheumatoid arthritis. Clin Exp Rheumatol 16 (6):745-749

\section{Figures}

\section{NDV}

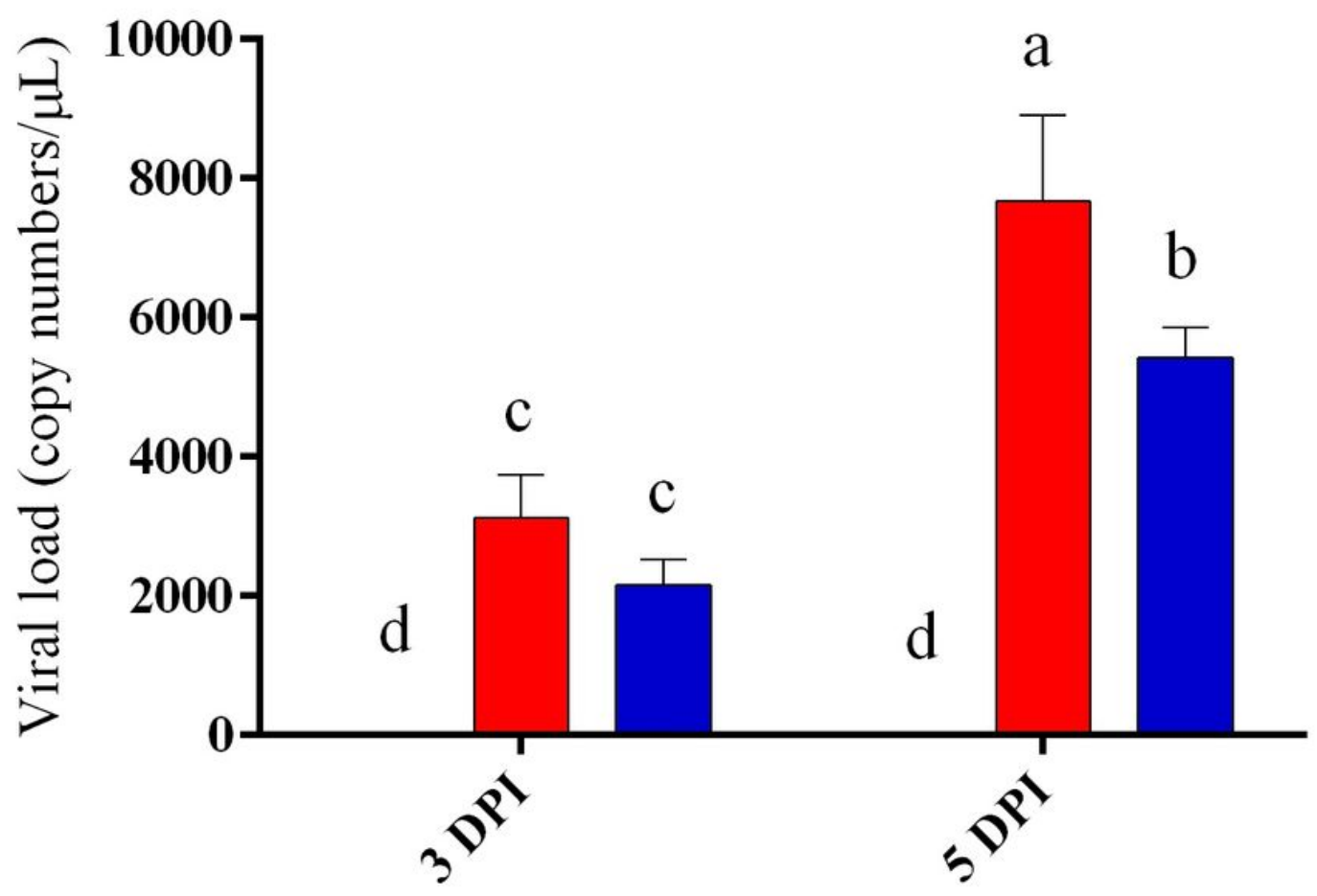

$\square \mathrm{CON}$

$\square$ CHA

- $\mathrm{VAC}+\mathrm{CHA}$

Figure 1

The viral copy numbers per $\mu \mathrm{l}$ are shown in the Figure 1. 


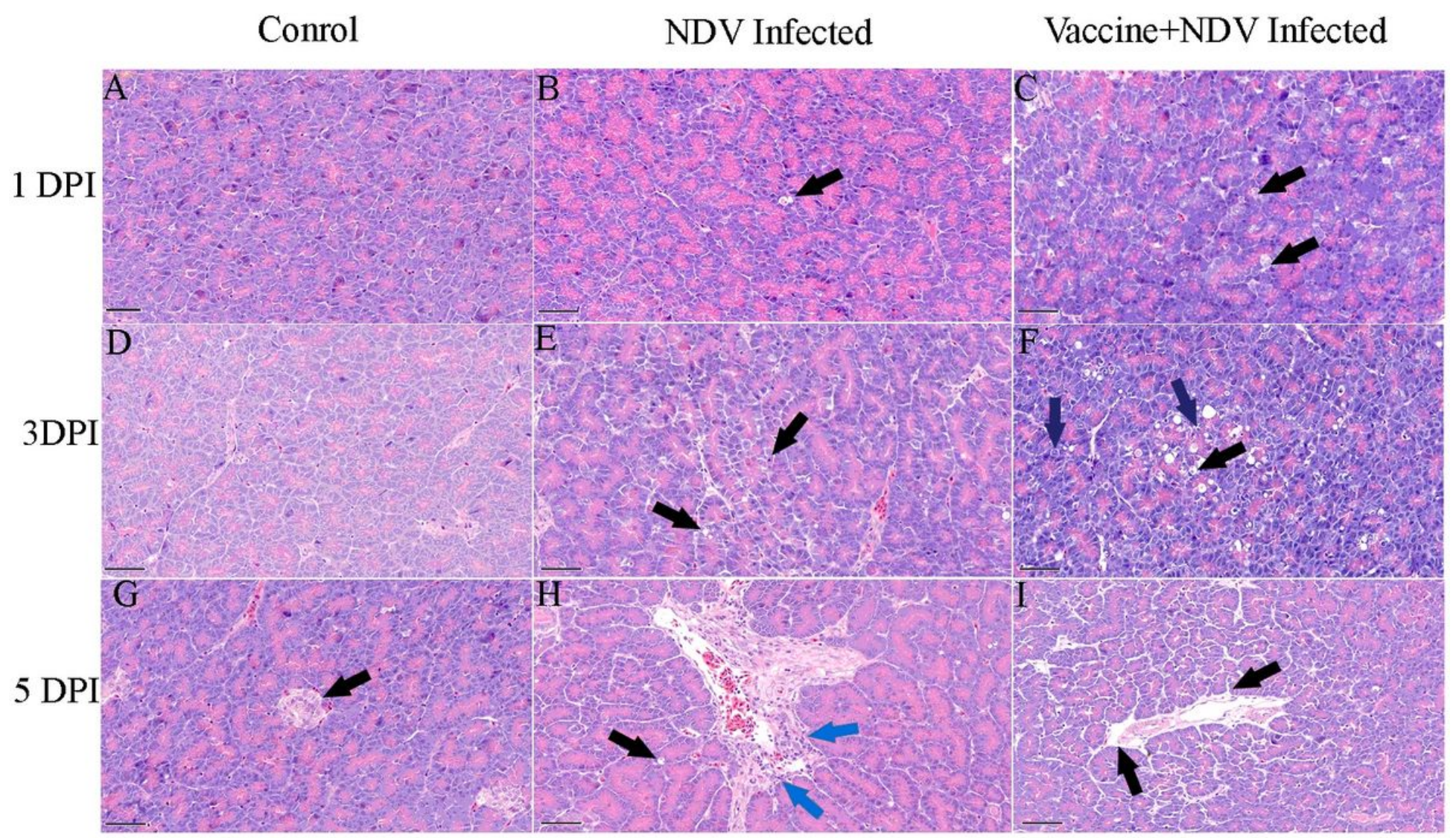

Figure 2

single cell necrosis 


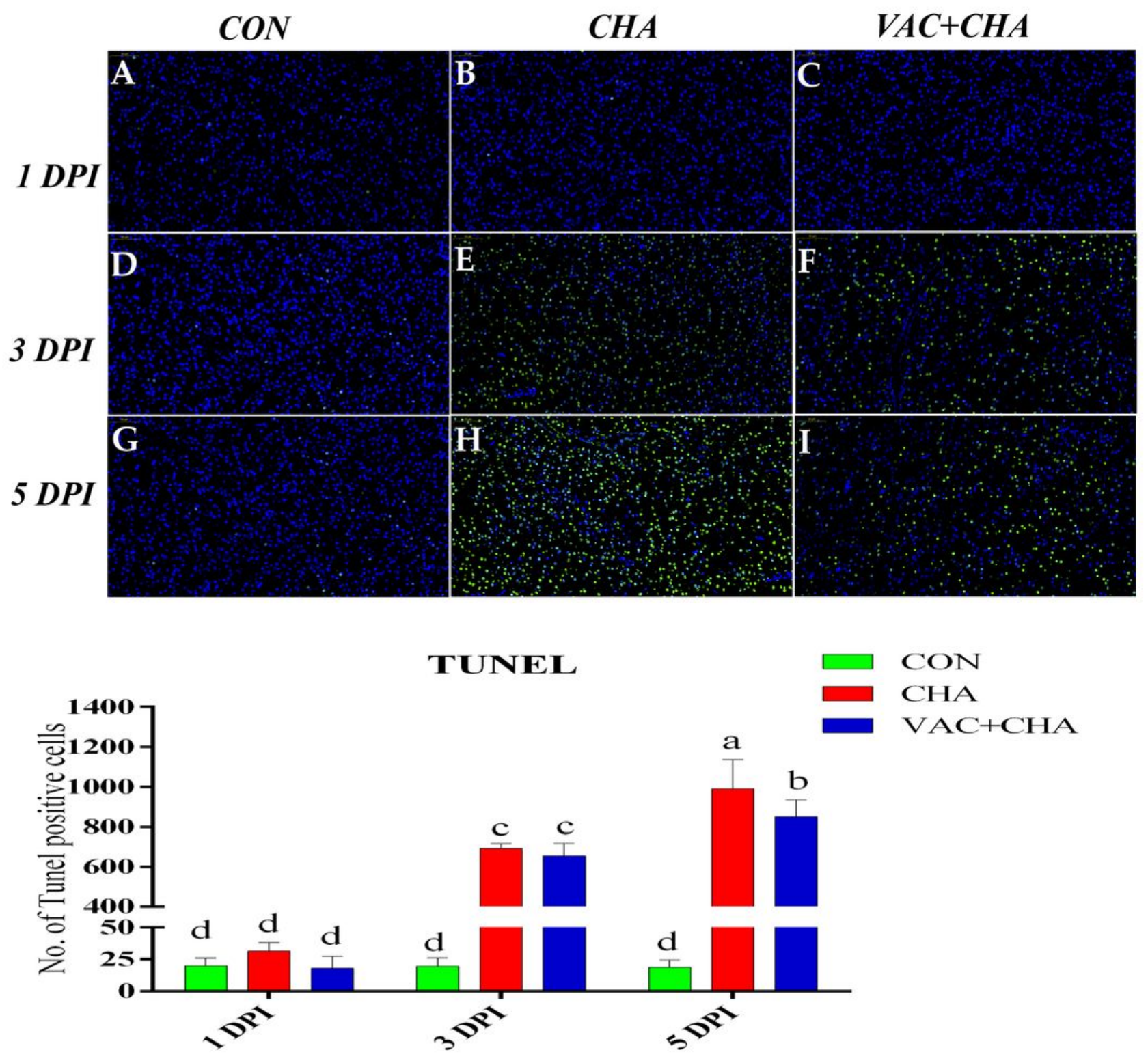

Figure 3

The number of apoptotic positive cells in the pancreas was similar between the CON and NDV infected groups at 1 DPI. 
(A)

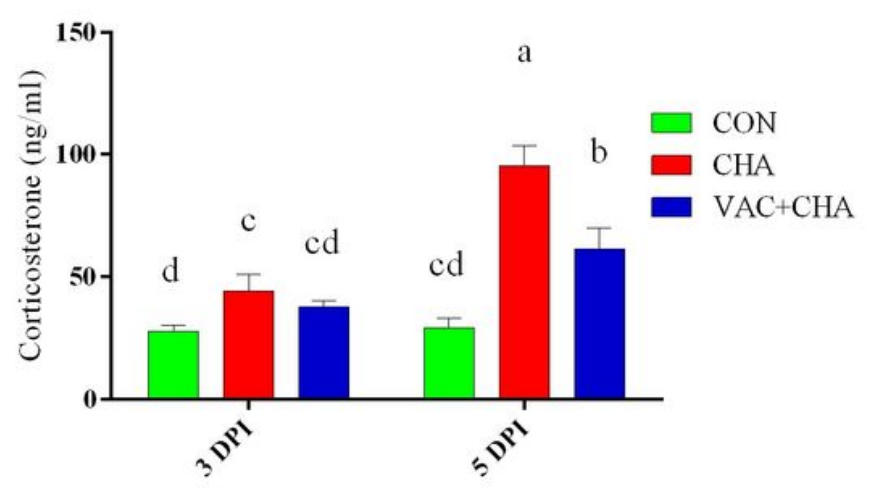

(C) $\square \mathrm{CON}$

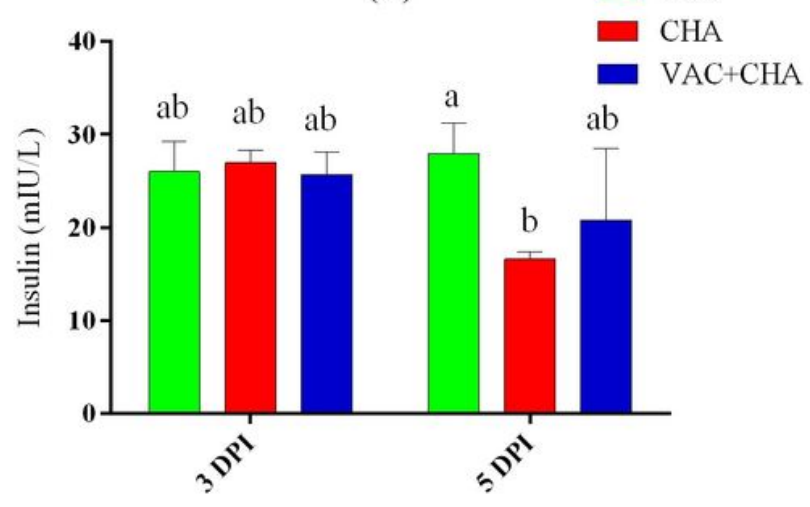

(B)

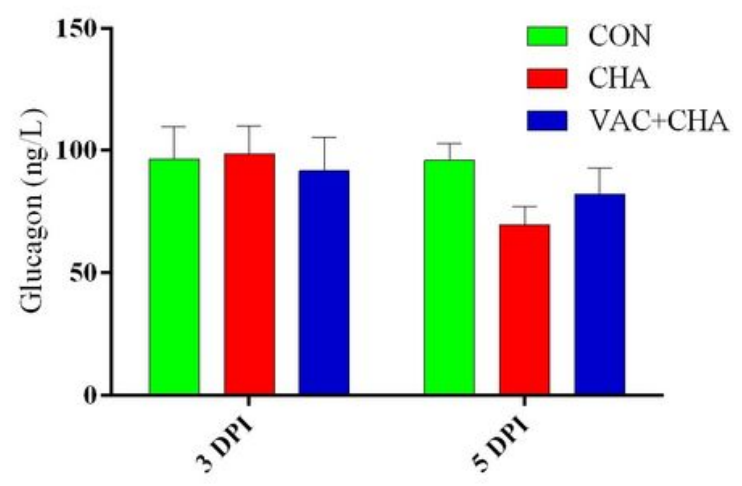

(D)

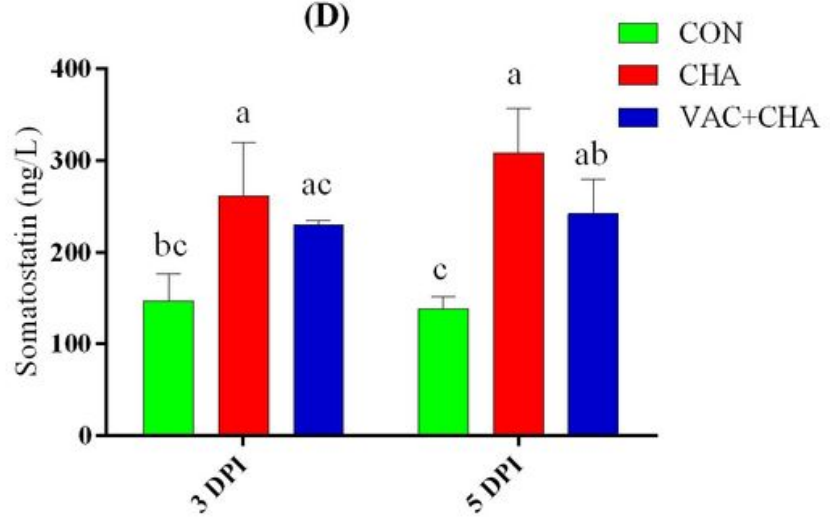

Figure 4

Plasma concentration of the somatostatin 
A

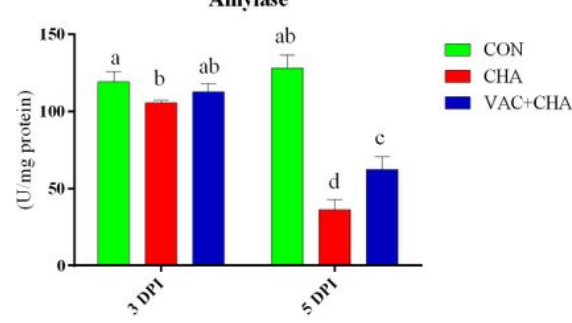

C

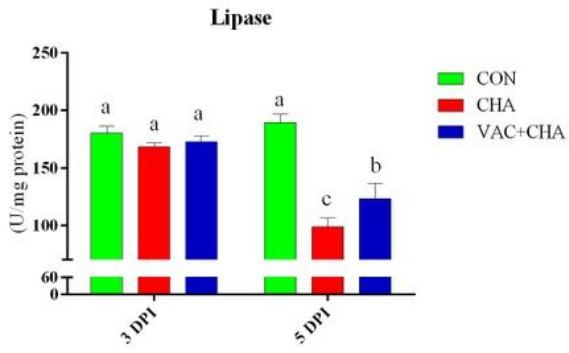

E

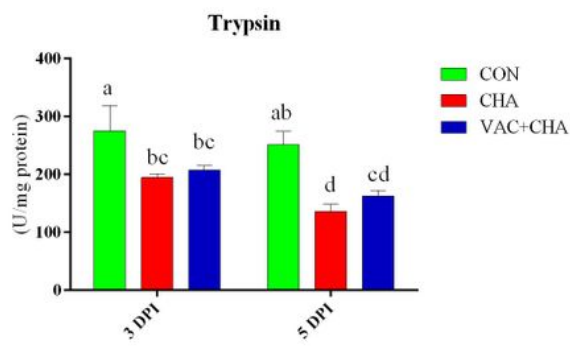

B

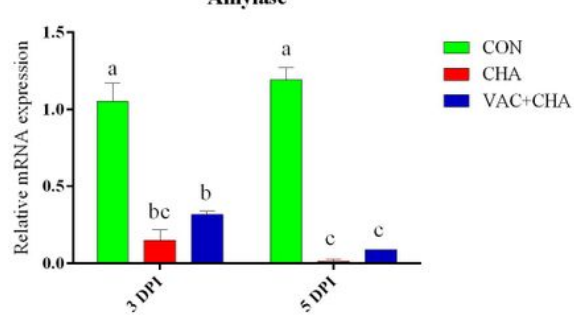

D

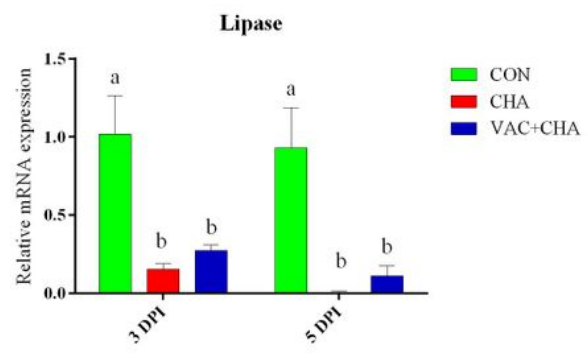

$\mathbf{F}$

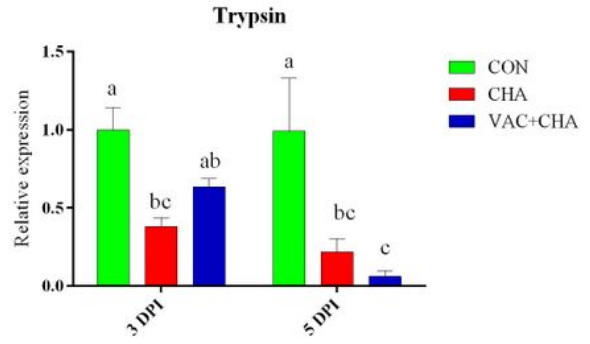

Figure 5

There was non-significant effect of NDV challenge in SPF and vaccinated chickens on the activity of lipase at 3 DPI 